\title{
SOME INEQUALITIES OF OPERATOR MONOTONE FUNCTIONS
}

\section{HONGLIANG ZUO AND GUANGCAI DUAN}

Abstract. Let $f(t)$ be any non-constant operator monotone function on $[0, \infty)$ and also let $A$ and $B$ be strictly positive operators:

(i) If $A>B$, then

$$
f\left(A^{\alpha}\right)-f\left(B^{\alpha}\right) \geqslant f\left(\left\|A^{\alpha}\right\|\right)-f\left(\left\|A^{\alpha}\right\|-\frac{1}{\left\|\left(A^{\alpha}-B^{\alpha}\right)^{-1}\right\|}\right)>0
$$

for all $\alpha \in(0,1]$.

(ii) If $\log A>\log B$, then there exists $\beta \in(0,1]$ such that

$$
f\left(A^{\alpha}\right)-f\left(B^{\alpha}\right) \geqslant f\left(\left\|A^{\alpha}\right\|\right)-f\left(\left\|A^{\alpha}\right\|-\frac{1}{\left\|\left(A^{\alpha}-B^{\alpha}\right)^{-1}\right\|}\right)>0
$$

for all $\alpha \in(0, \beta]$.

Mathematics subject classification (2010): 15A45.

Keywords and phrases: Operator monotone function, strictly positive operator, chaotic order, LöwerHeinz inequality.

\section{REFERENCES}

[1] R. Bhatia, Matrix Analysis, New York: Springer Verlag, 1997.

[2] M. FujII, Furuta inequality and its related topics, Ann. Funct. Anal. 1, 1 (2010), 28-45.

[3] M. FUJII, J. F. JiANG AND E. KAMEI, Characterization of chaotic order and its application to Furuta inequality, Proc. Amer. Math. Soc. 125 (1997), 3655-3658.

[4] T. FURUTA, Comprehensive survey on an order preserving operator inequality, Banach J. Math. Anal. 7, 1 (2013), 14-40.

[5] T. FurutA, Operator monotone functions, $A>B>0$ and $\log A>\log B$, J. Math. Inequal. 7, 1 (2013), 93-96.

[6] M. Moslehian And H. NAJAFI, An extension of the Löwner-Heinz inequality, Linear Algebra Appl. 437 (2012), 2359-2365.

[7] X. ZHAN, Matrix Inequalities, Berlin: Springer Verlag, 2002. 